\title{
Antiperspirant Cream F511
}

National Cancer Institute

\section{Source}

National Cancer Institute. Antiperspirant Cream F511. NCI Thesaurus. Code C88282.

A cream formulation containing aluminum chlorohydrate with astringent and antiperspirant activities. Upon topical application of F511 cream, aluminium chlorohydrate forms a gel matrix in the sweat gland which subsequently reduces, then stops the flow of water. In addition, this agent exerts an astringent effect, thereby further preventing sweat formation. Hyperhidrosis appears to play a role in the development of certain mucocutaneous reactions, such as palmar-plantar erythrodysesthesia (PPE), upon administration of chemotherapeutic agents such as doxorubicin, 5-fluorouracil, and capecitabine. 